\title{
Medicine and diplomacy
}

Prof Tommy Koh

\section{SIMILARITIES BETWEEN DOCTORS AND DIPLOMATS}

I shall begin with my first point, which is that doctors and diplomats share some common traits and values. You can't be a good doctor or a good diplomat if you do not like people. To succeed in our professions, we must have empathy for people. We must have an open mind and be willing to treat people of different races, colours, religions and cultures with respect and as fellow human beings. To be a good doctor, you have to establish a rapport with your patient and gain his trust and confidence. The doctor-patient relationship becomes dysfunctional when the patient dislikes his doctor or has no confidence in him. I have no empirical evidence to support my hypothesis that a patient's positive attitude towards his doctor contributes a significant percentage to the success of the healing process. My hypothesis is that a patient's trust in his doctor is a key to recovery.

In a similar way, a good diplomat is able to establish a rapport with his interlocutor. He should try to raise the level of their relationship to one of friendship, based upon mutual trust and confidence. I have undertaken many negotiations on behalf of Singapore and the United Nations (UN). In all cases, I had tried to establish a warm relationship with my counterpart or interlocutors. This was particularly challenging when I was chairing the UN Conference on the Law of the Sea (1981 to 1982) and the Earth Summit (1990 to 1992), because they involved so many participating countries. However, I could not have pushed through some very tough decisions if I had not gained the trust of the conference participants.

\section{Breakthrough in Moscow}

Diplomats, unlike doctors, are a pretty cynical group of people. They have become cynical because they have seen so much evil and unprincipled policies and actions by states. Also, unlike doctors, diplomats are professional nomads and have to relocate themselves and their families every few years to a different country. In view of these facts, it would be reasonable to conclude that diplomats do not make good friends. This is, however, not the case.

\section{Ambassador Tom Pickering}

I want to tell you a story that I have never told in public before. In 1993, the then UN Secretary-General, Dr Boutros Boutros-Ghali, had appointed me as his Special Envoy to undertake a peace mission to Russia, Estonia, Latvia and Lithuania. Towards the end of my mission, I called on an old friend in Moscow, Ambassador Tom Pickering of the United States (US). I briefed him on my discussions in Moscow, Vilnius, Riga and Tallinn. He told me that, in Moscow, power was concentrated in the Kremlin and it was essential for me to have access to someone on the personal staff of President Boris Yeltsin. I told Ambassador Pickering that
I had made a request to do so through the $U N$ and the Singapore Embassy but was unsuccessful. He told me that he would help me, and he did. As a result, I was able to meet with a senior member of the President's staff inside the Kremlin. I briefed him on my meetings in the four capitals and the compromises that I intended to propose in my report to the $\mathrm{UN}$. I then requested him to convey my respect to President Yeltsin and pleaded for his support.

\section{REGIONAL MEDICAL CENTRE}

I want to go on to my second point, which is Singapore's role as the medical centre of the region. No one could dispute the fact that Singapore is the most advanced medical centre in Southeast Asia and, perhaps, the whole of Asia. A few years ago, a good friend from Iran, who lives in Hiroshima, needed surgery for a medical condition. Her Japanese doctor in Hiroshima recommended that she should seek treatment either in the US or Singapore for her treatment. She chose to come here.

Many of our region's leaders come to Singapore for their annual medical check-up. When they fall ill, many of them have chosen to come here for treatment rather than go to the West. The high standing of our doctors and hospitals and the excellent care and services that they provide to patients in the region bring credit to Singapore. It adds to our brand equity and soft power. It is good for our diplomacy with the region. We must never allow our love for money to undermine our reputation for integrity and trustworthiness.

\section{SINGAPORE AND WHO}

Thirdly, I want to talk about Singapore's relationship with the World Health Organization (WHO). WHO is the UN's specialised agency for global health. In the year 2000, WHO ranked Singapore sixth out of 191 countries on overall health system performance. $\mathrm{WHO}$ has designated ten of our institutions as WHO Collaborating Centres, one of the highest in the Asia-Pacific region. These are research institutes belonging to universities or academies that have been designated by WHO to carry out activities in support of its programme.

\section{SARS}

In 2003, Singapore and several other countries in the region were hit by SARS (severe acute respiratory syndrome). Singapore worked closely with WHO and the Centers for Disease Control and Prevention of the US to overcome the crisis. The two big lessons we learnt from that crisis were the importance of transparency and international cooperation. In 2006, Singapore was elected to the Executive Board of WHO for a three-year term. My dear friend and colleague, the late Dr Balaji Sadasivan, was elected chairman of the board from 2007 to 2008 . His untimely passing from colon cancer was a great loss to Singapore.

Other Singaporeans, such as Dr Vernon Lee and Mr David Ho, have also made significant contributions to the work of 
WHO. Dr Lee is currently the Head of the Singapore Armed Forces (SAF) Biodefence Centre. From 2007 to 2008, Dr Lee was a medical epidemiologist working on avian influenza response and pandemic preparedness in the WHO office in Indonesia. From 2010 to 2012, he worked with WHO in Geneva, leading its work on global health collaborations and pandemic preparedness. I will not talk about Mr David Ho's work because he is not a doctor.

\section{HUMANITARIAN MEDICAL MISSIONS}

Fourth, I want to refer to the fact that many Singaporean doctors, dentists, nurses, therapists and other allied professionals regularly go abroad on humanitarian medical missions. I was privileged to have been invited to deliver the keynote speech at the inaugural International Conference on Humanitarian Medical Missions, held on 30 October 2014, at the Singapore General Hospital.

In my speech, I praised the work of four of our institutions, namely the Singapore International Foundation (SIF), the SAF, the Singapore Red Cross Society and Mercy Relief. To date, SIF has undertaken 76 healthcare projects in 14 countries. SAF has a tradition of sending medical teams to help in emergency situations. The Singapore Red Cross Society and Mercy Relief have also despatched volunteer medical teams to help in humanitarian emergencies.

I am proud to say that our public hospitals also support volunteerism as part of their corporate social responsibility. Members of the staff are encouraged to volunteer their time in both local and international projects. A staff member is allowed to take 14 days of volunteer leave if it is to participate in an approved project. In 2011, KK Women's and Children's Hospital (KKH) won the award for the Public Sector Volunteer of the Year, given annually by the National Volunteer and Philanthropy Centre.

\section{Champion volunteers}

In that same speech, I also praised four of my doctor friends who are champion volunteers. They are Prof Lee Seng Teik of SGH (Singapore General Hospital), Prof Anantharaman Venkataraman (Prof Anantha) of SGH, A/Prof Anette Jacobsen of KKH and Dr Tan Chi Chiu, a private practitioner.

Prof ST Lee is a highly skilled plastic surgeon and educator. In the past 22 years, he has led or participated in 22 volunteer missions to ASEAN countries and China. In recognition of his contributions, he received the SIF Award from President SR Nathan in 2006.

Prof Anantha is another veteran volunteer. He was the leader of a highly successful SIF project to enhance emergency medical services in Malang, Indonesia. The project lasted seven years and involved 96 volunteers from Singapore, who visited Malang on 17 training visits. The project benefited the Faculty of Medicine of the Saiful Anwar Hospital, the Faculty of Medicine of the Brawijaya University and the Provincial Health Department of East Java. Prof Anantha is currently leading a team from SingHealth, on a two-year project, to set up a Disaster Medical Training System in Makassar, Sulawesi, Indonesia.

A/Prof Anette Jacobsen is a paediatric surgeon at $\mathrm{KKH}$. In 2001, she went on her first volunteer mission to Cambodia and was hooked. Since then, she has been on over 20 missions to four ASEAN countries. She volunteers with SIF, the Temasek Foundation and the Tzu Chi Foundation of Taiwan.

Dr Tan Chi Chiu is an eminent gastroenterologist in private practice and a former director of SIF. He is one of our most experienced volunteers. Between 1986 and 2013, he participated in 14 humanitarian medical missions, in 12 of which he was the leader or medical director. Dr Tan believes that Singapore can do more and should benchmark itself against Japan and South Korea. He proposes the creation of a national network and resource of medical volunteers, which could then support the relief missions of all organisations that need medical teams.

\section{People-to-people diplomacy}

What is the significance of medical volunteerism to Singapore's diplomacy, especially with the ASEAN countries? We live in a world that is full of misunderstanding and suspicion. Medical volunteers help to promote better mutual understanding between Singaporeans and the peoples of other countries. The work that our doctors, dentists, nurses, therapists and other allied professionals do on medical missions is invaluable. Action speaks louder than words.

\section{FRIENDSHIP BETWEEN CHINA AND SINGAPORE}

Fifth, and finally, I want to talk about the contributions of three Singapore doctors to friendship between China and Singapore. The three doctors are the late Prof Arthur Lim Siew Ming, Prof Lim Yean Leng and Dr Tan Lai Yong.

Prof Arthur Lim was an eminent ophthalmologist, a visionary and a man of action. He was the founding director of Singapore National Eye Centre. In the 1980s, he led a major campaign in China to control mass cataract blindness. He advocated the use of intraocular lens implant to restore sight. He founded the International Intraocular Implant Training Centre in Tianjin, which, in 1986, became the Tianjin Medical University Eye Centre. Prof Lim established the Xiamen Eye Centre in 1997. He also established eye centres in three other provinces: Shandong, Gansu and Ningxia. In 1996, the Chinese government conferred on Prof Lim the Friendship Award, which is the highest award presented to a foreign national.

Prof Lim Yean Leng is an eminent cardiologist and the former director of the National Heart Centre in Singapore. In 1995, he was invited to visit Xiamen by his mother's primary school classmate. At that time, Xiamen University, which was founded by Singaporean Tan Kah Kee, had no medical school. As they say, one thing led to another and Prof Lim was appointed as the Dean of Xiamen University's new Medical College, as well as Head of the Heart Centre. The new medical school opened a year later, in 1996. Prof Lim served as the Dean for five years, setting up the Medical School, Heart Centre and Emergency Centre. He leaves behind a proud legacy. Today, the medical faculty of Xiamen University is one of the largest and most comprehensive medical schools in China. There are 1,500 undergraduates and 200 postgraduate students at the school. 


\section{Fujian-Singapore Friendship Polyclinic}

Before moving on from Xiamen, I want to record the fact that due to the vision and leadership of our former Consul-General in Xiamen, Ms Tee Bee Lock, we have the Fujian (Xiamen)Singapore Friendship Polyclinic. The polyclinic was co-funded by donations from the Singapore private sector and the Xiamen Municipal Government. An eminent Singapore architect, Liu Thai Ker, designed the building on a pro bono basis. The Temasek Foundation funded the training of 110 medical personnel from Fujian, on a 'train the trainers' programme. The polyclinic has successfully incorporated and implemented Singapore's health management strategies in its operation.

The third doctor I want to refer to is Dr Tan Lai Yong. In 1996, Dr Tan accepted a one-year assignment to join a commune in Yunnan province, to train its ethnic minority community in basic medical practice. His one-year assignment became a 15-year epic. He and his family lived humbly with the local people and won their hearts. He treated the poor, the orphaned, the disabled and the leprous. In addition to treating the locals, Dr Tan also began a tree-planting programme, started a mobile library for children and spearheaded other projects to benefit the people he lived with and served.

In 2004, the government of China conferred on Dr Tan the Friendship Award. In 2007, Yunnan TV conferred on him the Good Citizen of Kunming Award. Dr Tan is now back in Singapore and inspiring the students of the College of Alice and Peter Tan at NUS.

\section{CONCLUSION}

I shall conclude. As doctors, you are probably unaware that, directly or indirectly, many of you have been helping to promote Singapore's good relations with our ASEAN partners or the wider world. You do so when you do a good job in treating a foreign patient. You do so when you go on a humanitarian medical mission. You do so when you work with WHO or other kindred institutions. You do so if you, like Prof Arthur Lim, Prof Lim Yean Leng and Dr Tan Lai Yong, use your knowledge, expertise and network to help the people of another country, such as China.

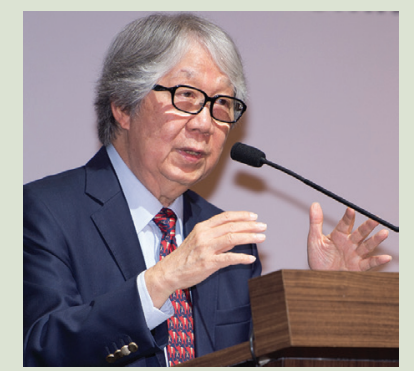

\section{About the Lecturer}

Professor Tommy Koh is currently Ambassador-At-Large at the Ministry of Foreign Affairs; Rector of Tembusu College; Governor of the Lee Kuan Yew School of Public Policy; Chairman of the International Advisory Panel of the Asia Research Institute; Special Adviser of the Institute of Policy Studies and Chairman of the Centre for International Law, National University of Singapore. He is also Chairman of the SymAsia Foundation of Credit Suisse and Co-Chairman of the China-Singapore Forum, the India-Singapore Strategic Dialogue and the Japan-Singapore Symposium.

The 2015 SMA Lecture was delivered on 7 November 2015 at the One Farrer Hotel and Spa. The citation of Prof Tommy Koh was delivered by Prof Cheah Jin Seng, Emeritus Consultant, Endocrinologist, National University Hospital. A copy of the citation was published in the December 2015 issue of the SMA News. 